\title{
In Vitro and In Vivo Antileishmanial Effects of Pistacia khinjuk against Leishmania tropica and Leishmania major
}

\author{
Behrouz Ezatpour, ${ }^{1}$ Ebrahim Saedi Dezaki, ${ }^{2}$ Hossein Mahmoudvand, ${ }^{2}$ \\ Mojgan Azadpour, ${ }^{1}$ and Fatemeh Ezzatkhah ${ }^{1}$ \\ ${ }^{1}$ Razi Herbal Medicines Research Center, Lorestan University of Medical Sciences, Khorramabad 6814994688, Iran \\ ${ }^{2}$ Leishmaniasis Research Center, Kerman University of Medical Sciences, Kerman 7616914111, Iran
}

Correspondence should be addressed to Hossein Mahmoudvand; dmahmodvand@gmail.com

Received 20 December 2014; Revised 19 February 2015; Accepted 20 February 2015

Academic Editor: Daniela Rigano

Copyright (C) 2015 Behrouz Ezatpour et al. This is an open access article distributed under the Creative Commons Attribution License, which permits unrestricted use, distribution, and reproduction in any medium, provided the original work is properly cited.

\begin{abstract}
The present study aims to evaluate the in vitro and in vivo antileishmanial activities of Pistacia khinjuk Stocks (Anacardiaceae) alcoholic extract and to compare its efficacy with a reference drug, meglumine antimoniate (MA, Glucantime), against Leishmania tropica and Leishmania major. This extract $(0-100 \mu \mathrm{g} / \mathrm{mL})$ was evaluated in vitro against promastigote and intracellular amastigote forms of L. tropica (MRHO/IR/75/ER) and then tested on cutaneous leishmaniasis (CL) in male BALB/c mice with $L$. major to reproduce the antileishmanial activity topically. In vitro, $P$. khinjuk extract significantly $(P<0.05)$ inhibited the growth rate of promastigote $\left(\mathrm{IC}_{50} 58.6 \pm 3.2 \mu \mathrm{g} / \mathrm{mL}\right)$ and intramacrophage amastigotes $(37.3 \pm 2.5 \mu \mathrm{g} / \mathrm{mL})$ of $L$. tropica as a dose-dependent response. In the in vivo assay, after 30 days of treatment, $75 \%$ recovery was observed in the infected mice treated with $30 \%$ extract. After treatment of the subgroups with the concentration of 20 and $30 \%$ of P. khinjuk extract, mean diameter of lesions was significantly $(P<0.05)$ reduced. To conclude, the present investigation demonstrated that $P$. vera extract had in vitro and in vivo effectiveness against $L$. major. Obtained findings also provide the scientific evidences that natural plants could be used in the traditional medicine for the prevention and treatment of CL.
\end{abstract}

\section{Introduction}

Cutaneous leishmaniasis (CL) is caused by the transmission of Leishmania spp. through the bite of female sandfly. This disease is characterized by chronic skin lesions and leaves permanent scars as deformation of the infected area [1]. CL is a public health problem with the annual incidence rate of 1.5 million people throughout the world. According to World Health Organization's (WHO) report, 12 million people are infected by parasites and 350 million people are living in regions with the high risk of infection [2]. In Iran, both epidemiological forms of this skin disease are present: anthroponotic CL (ACL) and zoonotic CL (ZCL) caused by Leishmania tropica and Leishmania major, respectively [3]. At present, the current medications used to treat leishmaniasis such as meglumine antimoniate and sodium stibogluconate are a challenge due to having problems of emerging resistance, high toxicity, or high costs [4]. Since there is no effective vaccine, maintenance and improvement of existing treatment regimens, combined with new drug discovery initiatives, were found to be the only ways to guarantee continued control of CL [5].

Natural products, such as plants extract, either as pure compounds or as standardized extracts, provide unlimited opportunities for new drug discoveries because of the unmatched availability of chemical diversity $[6,7]$. The genus Pistacia belongs to the family Anacardiaceae. Among 15 known species of pistachios, only 3 species grow in Iran, which include P. vera, P. khinjuk, and P. atlantica [8]. P. khinjuk Stocks commonly grows in the Mediterranean and Middle Eastern countries for the last 3000 years. In Iran, this plant is called "khenjuk or kelkhong" and grows in the central, western, and eastern areas [9]. Different parts of the plant including resin, leaf, bark, fruit, and aerial parts have been used widely as traditional medicine for the treatment and prevention of various disease conditions such as stomach 


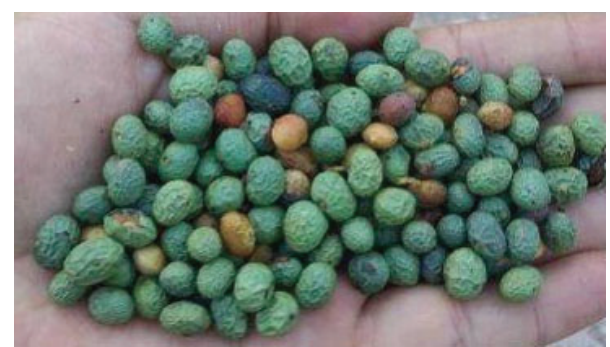

FIgure 1: Pistacia khinjuk fruit which is called "kelkhong" in Iran.

discomfort, nausea, vomiting, and motion sickness [10]. In addition, reviews have reported $P$. khinjuk to have antiinflammatory, antioxidant, antitumor, antiasthmatic, and antimicrobial properties [8]. The present study aims to evaluate the in vitro and in vivo antileishmanial activity of $P$. khinjuk extract and to compare its efficacy with a reference drug, meglumine antimoniate (MA, Glucantime) against L. tropica and L. major.

\section{Materials and Methods}

2.1. Chemicals. MA as a control drug was purchased from Aventis, France. Penicillin and streptomycin were obtained from Alborz Pharmacy, Karaj, Iran, and stored at room temperature $\left(25^{\circ} \mathrm{C}\right)$ until testing. MTT powder [3-(4.5dimethylthiazol-2-yl)-2.5-diphenyl tetrazolium bromide], fetal calf serum (FCS), fetal bovine serum (FBS), RPMI-1640 medium with L-glutamine, and Griess reagent (A and $B$ ) were prepared from Sigma-Aldrich (St. Louis, MO, USA). All other chemicals and solvents had the highest commercially available purity.

2.2. Collection of Plant Materials. Fruits of P. khinjuk were collected from rural regions of Kerman province, south east of Iran, from May to September 2013 (Figure 1). They were identified by a botanist of Botany Department of Shahid Bahonar University of Kerman, Kerman, Iran. A voucher specimen of the plant materials was deposited at the herbarium of Department of Pharmacognosy, School of Pharmacy, Kerman University of Medical Sciences, Iran (KF 1135).

2.3. Preparation of Extract. Air-dried plant materials (100 g) were separately extracted by percolation method with $70 \%$ aqueous ethanol successively for $72 \mathrm{~h}$ at room temperature. The extracts were passed through filter paper (Whatman number 3, Sigma, Germany) to remove plant debris. The extracts were finally concentrated in vacuum at $50^{\circ} \mathrm{C}$ using a rotary evaporator (Heidolph, Germany) and stored at $-20^{\circ} \mathrm{C}$ until testing [11].

2.4. Phytochemical Analysis. The preliminary phytochemical analysis of the P. khinjuk ethanolic extract was carried out to determine the presence of tannins, saponins, alkaloids, flavonoids, and glycosides as described elsewhere using the following reagents and chemicals [12]: alkaloids with Mayer and Dragendorff's reagents, flavonoids with the use of $\mathrm{Mg}$ and $\mathrm{HCl}$, tannin with $1 \%$ gelatin and $10 \% \mathrm{NaCl}$ solutions, glycosides with $\mathrm{FeCl}_{2}$ and $\mathrm{H}_{2} \mathrm{SO}_{4}$, and saponin with ability to produce suds.

2.5. Parasite and Cell Culture. Standard strains of L. tropica (MHOM/IR/2002/Mash2) and L. major (MRHO/IR/75/ER) were kindly prepared from Center for Research and Training in Skin Diseases and Leprosy, Tehran, Iran. The parasites were cultured at RPMI 1640 supplemented with penicillin $(200 \mathrm{IU} / \mathrm{mL})$, streptomycin $(100 \mu \mathrm{g} / \mathrm{mL})$, and $15 \%$ heatinactivated FCS. Murine macrophage cells (J774-A1) were obtained from Pasteur Institute of Iran, Tehran, Iran. The cells were cultured and maintained at Dulbecco's modified eagle's medium (DMEM) supplemented with $10 \% \mathrm{FBS}$ at $37^{\circ} \mathrm{C}$ in $5 \% \mathrm{CO}_{2}$.

2.6. Cytotoxic Effects. In order to determine the cytotoxic effects of $P$. khinjuk, J774-A1 cells $\left(5 \times 10^{5}\right)$ were cultivated with various concentrations of alcoholic extract ( 0 to $5000 \mu \mathrm{g} / \mathrm{mL})$ in 96 -well tissue culture plates at $37^{\circ} \mathrm{C}$ in $5 \%$ $\mathrm{CO}_{2}$ for $48 \mathrm{~h}$. Cell viability was determined by colorimetric MTT assay and the results were displayed as the percentage of dead cells compared to macrophages treated with MA and nontreated macrophages (100\% of viability) [13].

\subsection{In Vitro Antileishmanial Activity}

2.7.1. Antipromastigote Assay. To evaluate the antipromastigoteeffects of $P$. khinjuk ethanolic extract against promastigote forms of L. tropica, colorimetric cell viability MTT assay was used as described elsewhere [14]. At first, $100 \mu \mathrm{L}$ of the promastigotes $\left(10^{6}\right.$ cells $\left./ \mathrm{mL}\right)$ harvested from logarithmic growth phase was added to a 96-well tissue culture plate. Then, $100 \mu \mathrm{L}$ of various concentrations of alcoholic extract and MA $(0-100 \mu \mathrm{g} / \mathrm{mL})$ was added to each well and incubated at $25 \pm 1^{\circ} \mathrm{C}$ for $48 \mathrm{~h}$. After the incubation, $10 \mu \mathrm{L}$ of MTT solution $(5 \mathrm{mg} / \mathrm{mL})$ was added to each well and incubated at $25^{\circ} \mathrm{C}$ for $4 \mathrm{~h}$. Promastigotes were cultured at complete medium with no drug as positive control and complete medium with no promastigotes and drugs as blank. The absorbance was measured for each well at $560 \mathrm{~nm}$ using an ELISA reader (BioTek-ELX800, USA).

2.7.2. Antiamastigote Assay. In this study, antiamastigote activity of $P$. khinjuk extract was performed using the methods described by Mahmoudvand et al. [15]. Briefly, before adding the macrophages to the plates, $1 \mathrm{~cm}^{2}$ cover slips were placed in the wells of 6-chamber slides (Lab-Tek, Nalge Nunc International, NY, USA). In the next step, $200 \mu \mathrm{L}$ of macrophage (J774) cells $\left(10^{5} / \mathrm{mL}\right)$ was incubated at $37^{\circ} \mathrm{C}$ in $5 \%$ $\mathrm{CO}_{2}$ for $2 \mathrm{~h}$. Then, $200 \mu \mathrm{L}\left(10^{6} / \mathrm{mL}\right)$ promastigotes in stationary phase was added to the murine macrophages so that proportion of Leishmania/macrophage was 10:1 and incubated again in a similar condition for $24 \mathrm{~h}$. Free parasites were removed by washing with RPMI 1640 medium and the infected macrophages were treated with $50 \mu \mathrm{L}$ of various concentrations of $0-100 \mu \mathrm{g} / \mathrm{mL}$ alcoholic extract at $37^{\circ} \mathrm{C}$ in 
$5 \% \mathrm{CO}_{2}$ for $72 \mathrm{~h}$. Finally, the dried slides were fixed with methanol, stained by Giemsa, and studied under a light microscope. Also, the macrophages containing amastigotes without extract and those with no parasite and extract were considered positive and negative controls, respectively. Activity of anti-intramacrophage amastigotes of the extracts was evaluated by counting the number of amastigotes in each macrophage by examining 100 macrophages (\% amastigotes viability) in comparison with those obtained by positive control.

2.7.3. Inhibition of Infection in Macrophage Cells. The inhibitory effect of $P$. khinjuk extract against the promastigotes invasion of macrophages, as one of the most important pathogenic and biological criteria of Leishmania parasites, was investigated. In this assay, promastigotes of L. tropica were preincubated in $P$. khinjuk extract $(5 \mu \mathrm{g} / \mathrm{mL})$ for $2 \mathrm{~h}$ at room temperature. Then promastigotes were washed with RPMI-1640 medium and incubated with macrophage cells for $24 \mathrm{~h}$. The macrophages were stained by Giemsa and studied by a light microscope, to evaluate the frequency of infection by counting 100 macrophages [3].

2.7.4. Nitric Oxide Production Determination. In this study, nitric oxide (NO) release in supernatants of macrophage culture was measured by the Griess reaction for nitrites compared to the untreated macrophages. One hundred $\mu \mathrm{L}$ of supernatants was collected $48 \mathrm{~h}$ after introducing the various concentrations of $P$. khinjuk extract $(3.125,6.25$, and 12.5) into the culture medium. The assay was done in triplicate wells in a 96-well tissue culture plate. To this, $60 \mu \mathrm{L}$ of Griess reagent $\mathrm{A}$ and then $60 \mu \mathrm{L}$ of Griess reagent B were added. The plates were read at $540 \mathrm{~nm}$ in an ELISA plate reader (BioTekELX800, USA).

\subsection{In Vivo Antileishmanial Activity}

2.8.1. Ethical Statement. The experimental procedures carried out in this survey were in compliance with Guidelines of Kerman University of Medical Science (Kerman, Iran) for the care and use of laboratory animals in line with Animal Ethics Committee (permit number 91/21).

2.8.2. Animals. Thirty-two male BALB/c mice (6-8 weeks old) were obtained from Animal Breeding Stock Facility, Razi Institute of Iran, Karaj, Iran. The animals were housed in a colony room with a $12: 12 \mathrm{~h} \mathrm{light/dark}$ cycle at $21 \pm 2^{\circ} \mathrm{C}$ and handled according to standard protocols for the use of laboratory animals [16].

2.8.3. Infecting of $B A L B / c$ Mice by Injecting of L. major. To infect the male $\mathrm{BALB} / \mathrm{c}$ mice, $0.1 \mathrm{~mL}$ of the promastigotes of L. major $\left(2 \times 10^{6}\right.$ cells $\left./ \mathrm{mL}\right)$ harvested from the stationary phase was subcutaneously injected into the base of the tail [17]. Thirty-two mice were divided into two groups; then, every group was divided into two subgroups; so, every group contained eight mice (Figure 2).

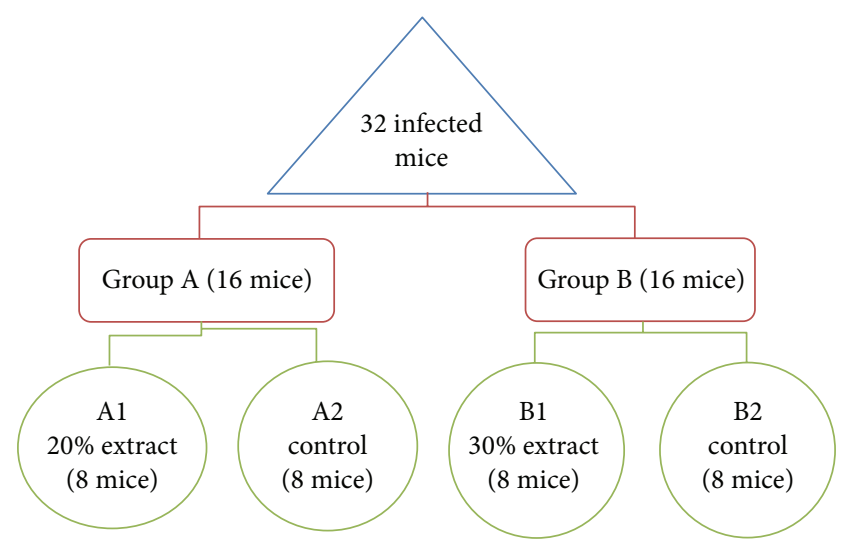

FIgure 2: Flow chart of in vivo antileishmanial activity of $P$. khinjuk alcoholic extract after 30-day application as intralesionally compared to meglumine antimoniate (MA) as control drug.

2.8.4. Treatment of Infected Mice. After 5 weeks when leishmanial lesions appeared, the treatment of infected mice was started. At first, the diameter of lesions was measured before the treatment. Then, lotion $(5 \mathrm{~g} / \mathrm{kg}$ ethanolic extract at the concentrations of 20 and 30\%) and MA were applied for each tested subgroup daily for 30 days topically. The control subgroups received distilled water and ethanol topically.

2.8.5. Measurement of Lesion Size. Before and after the treatment, the diameter of lesions was measured using vernier caliper in two diameters $(D$ and $d$ ) at right angles to each other, and the size $(\mathrm{mm})$ was determined according to the formula $S=(D+d) / 2[18]$.

2.8.6. Microscopical Examinations to Determine Parasite Load. Microscopical examinations were performed by laboratory demonstration of the parasite load in the lesions by making stained smears at the end of the experimental period. Lesions were cleaned with ethanol and punctured at the margins with a sterile lancet and exudation material was smeared. The smears were dried in air, fixed by methanol, and stained with Giemsa to determine the load of parasites by light microscopy as follows:

$$
\begin{aligned}
& \text { negative: } 0 \text { parasite/10 fields, } \\
& \text { 1+: } 1 \text { parasite/10 fields, } \\
& \text { 2+: 1-10 parasites/10 fields, } \\
& \text { 3+: 10-100 parasites/10 fields, } \\
& \text { 4+: 1010-1000 parasites/10 fields, } \\
& \text { 5+ and more: more than } 1000 \text { parasites/10 fields. }
\end{aligned}
$$

2.9. Statistical Analysis. In this survey, all the tests were carried out in triplicate. To determine $\mathrm{CC}_{50}$ (cytotoxic concentration for $50 \%$ of cells) and $\mathrm{IC}_{50}(50 \%$ inhibitory concentrations) lineal regression was used. Selectivity index (SI), calculated based on the equation of $\mathrm{CC}_{50}$ for murine macrophage cells $/ \mathrm{IC}_{50}$ for amastigote forms of $L$. tropica, was used to compare the toxicity and activity of ethanolic extract 
TABLE 1: Effect of various concentrations of P. khinjuk alcoholic extract before and after treatment on the size of lesions (cm) in Balb/c mice infected by L. major.

\begin{tabular}{lccc}
\hline Concentrations & Size of lesions $(\mathrm{cm})$ before treatment & Size of lesions $(\mathrm{cm})$ after treatment & $P$ value $^{\mathrm{b}}$ \\
\hline $20 \%$ & $1.31 \pm 0.29$ & $1.12 \pm 0.20$ & $<0.05$ \\
$30 \%$ & $1.28 \pm 0.29$ & $0.84 \pm 0.12$ & $<0.05$ \\
MA $^{\mathrm{a}}$ & $1.37 \pm 0.22$ & $0.42 \pm 0.12$ & $<0.05$ \\
Control & $1.23 \pm 0.25$ & $2.09 \pm 0.26$ & - \\
\hline
\end{tabular}

${ }^{\mathrm{a}}$ Meglumine antimoniate.

${ }^{\mathrm{b}}$ Difference is significant when compared to control.

of P. khinjuk, as described by Weniger et al. [19]. Data analysis was carried out using SPSS statistical package, version 17.0 (SPSS Inc., Chicago, IL, USA). Differences between the test and control groups were analyzed by $t$-test. In addition, $P<$ 0.05 was considered statistically significant.

\section{Results}

3.1. Phytochemical Analysis. In this study, the findings of primary phytochemical screening of the ethanolic extract of P. khinjuk demonstrated the presence of high amount of tannins, phenols, and glycosides and lacking of the alkaloids in this plant.

\subsection{In Vitro Antileishmanial Effects}

3.2.1. Antipromastigote Activity. The results revealed that $P$. khinjuk alcoholic extract had remarkable antileishmanial activity against the promastigote forms of $L$. tropica based on a dose-dependent response $(P<0.05)$. $\mathrm{IC}_{50}$ value for the $P$. khinjuk extract and MA against promastigotes of L. tropica was $58.6 \pm 3.15 \mu \mathrm{g} / \mathrm{mL}$ and $88.3 \pm 4.05 \mu \mathrm{g} / \mathrm{mL}$, respectively.

3.2.2. Antiamastigote Assay. The findings demonstrated that, similar to promastigote stage, $P$. khinjuk extract significantly $(P<0.05)$ inhibited the growth rate of intramacrophage amastigotes as a dose-dependent response. The obtained $\mathrm{IC}_{50}$ values were $37.3 \pm 2.51 \mu \mathrm{g} / \mathrm{mL}$ and $44.6 \pm 2.51 \mu \mathrm{g} / \mathrm{mL}$ for the P. khinjuk extract and MA, respectively.

3.2.3. Inhibition of Infection. The results revealed that promastigote forms of $L$. tropica with no drugs were able to infect $84.3 \pm 6.5$ percent of macrophage cells. While promastigotes treated with the $P$. khinjuk had potency to infect only $38.6 \pm$ 3.05 percent of the macrophages cells, thus, these findings revealed that infectivity of promastigotes of $L$. tropica significantly reduced $(P<0.05)$ with $P$. khinjuk extract preincubation.

3.2.4. NO Production Determination. The findings of this assay demonstrated that the $P$. khinjuk at concentration of $3.125 \mu \mathrm{g} / \mathrm{mL}$ triggered production of $14.3 \pm 1.5 \mu \mathrm{M}$ of nitric oxide compared to the untreated macrophages with value of $11.3 \pm 0.5 \mu \mathrm{M}(P>0.05)$, whereas this extract at higher concentrations $(\geq 6.25 \mu \mathrm{g} / \mathrm{mL})$ decreased production of $\mathrm{NO}$

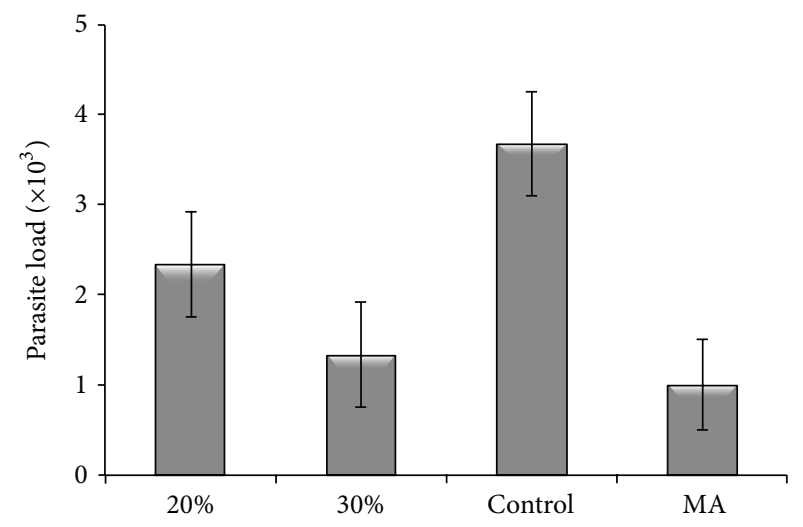

Figure 3: Comparison of parasite load in tested groups after treatment with various concentrations of $P$. khinjuk alcoholic extract.

to $\leq 7 \mu \mathrm{M}$, compared to the untreated macrophages $(P>$ $0.05)$.

3.2.5. Cytotoxic Effects. In the assessment of in vitro cytotoxic activity of alcoholic extract of $P$. khinjuk, it could be observed that $P$. khinjuk extract had no significant cytotoxicity against J774 cells. $\mathrm{CC}_{50}$ values for P. khinjuk extract and MA were $511.6 \pm 7.15 \mu \mathrm{g} / \mathrm{mL}$ and $1225.6 \pm 11.6$, respectively. SI values for the alcoholic extract P. khinjuk and MA are 13.7 and 27.5, respectively.

3.3. In Vivo Antileishmanial Effects. In vivo antileishmanial evaluation of the $P$. khinjuk alcoholic extract demonstrated that, in the infected mice treated with the extract concentration of $30 \%$, the number of parasites significantly $(P<$ 0.05 ) reduced with respect to MA, whereas $20 \%$ of the extract decreased the number of parasites intermediately. Control subgroups (distilled water and ethanol) had no decrease in the number of parasites (Figure 3). After 30 days of treatment, 75 and $87.5 \%$ recovery were observed in the infected mice treated with $30 \%$ extract and MA, respectively, while $P$. khinjuk extract at the concentration of $20 \%$ recovered $50 \%$ of the infected mice. After treatment of the subgroups with the concentration of $20 \%$ P. khinjuk extract, mean diameter of lesions was reduced to $0.19 \mathrm{~cm}$. In contrast, in the subgroups treated with $30 \%$ P. khinjuk extract, mean diameter of lesions was decreased to $0.44 \mathrm{~cm}$. In the positive subgroups, mean diameter of the lesions was reduced to $0.77 \mathrm{~cm}$ (Table 1). 


\section{Discussion}

According to WHO, more than $80 \%$ of the world's population rely on traditional medicine for their primary healthcare needs. In the past decades, the advent of synthetic antimicrobial drugs has caused reluctance in plants as a rich resource for antimicrobial agents [20] However, in recent years, the emergence of some limitations in the use of these drugs has caused changes in the situation and interest in the field of ethnobotanical research [21]. In the present investigation, the in vitro and in vivo antileishmanial activities of alcoholic extract of $P$. khinjuk were assessed against $L$. tropica and $L$. major. The obtained results of optical density (OD) and consequently $\mathrm{IC}_{50}$ values demonstrated that $P$. khinjuk alcoholic extract significantly inhibited the growth rate of promastigote forms of L. tropica. In addition, this extract significantly decreased mean infection rate and subsequently the viability of amastigote forms in the macrophages compared with the control group. The findings exhibited that amastigote forms were more susceptible to $P$. khinjuk extract than promastigote forms. This difference in the susceptibility of promastigote and amastigote forms could be related to their structural, biochemical, and morphological features as previously demonstrated by other researchers $[22,23]$. In the in vivo assay, it was found that $P$. khinjuk extract at the concentration of $30 \%$ had potent suppression effects on CL in male BALB/c mice infected with L. major with $87.5 \%$ recovery, whereas P. khinjuk extract at the concentration of $20 \%$ displayed the suppression effects as intermediate. In line with our results, it has been proven that gum obtained $P$. atlantica controlled cutaneous leishmaniasis in mice infected with $L$. major [24]. These results were in agreement with those of the previous studies, indicating that the commonly used herbs had antimicrobial properties that, in some cases, can be used in traditional medicine [25]. Previously, in several studies, antibacterial, antiviral, and antifungal effects of different parts of Pistacia species, particularly P. khinjuk, have been demonstrated [8]. However, there are few studies on the antiparasitic effects of Pistacia species including the study conducted by Orhan et al., which proved that $P$. vera branch extract at the concentration of $4.8 \mu \mathrm{g} / \mathrm{mL}$ significantly (77.3\%) inhibited the growth of $L$. donovani, whereas dry leaf extract (PVDL) was active against Plasmodium falciparum (60.6\% inhibition) [26]. This research also revealed that the $\mathrm{IC}_{50}$ values of these extracts were determined as $2.3 \mu \mathrm{g} / \mathrm{mL}$ for the amastigotes of $L$. donovani grown at axenic culture and $3.65 \mu \mathrm{g} / \mathrm{mL}$ for $P$. falciparum.

The preliminary phytochemical analysis of $P$. khinjuk extract demonstrated the presence of terpenoids, phenols, flavonoids, fatty acids, and sterols and lack of alkaloids in this plant. At present, individual activities of these compounds have been proven [20]. Moreover, different studies have shown potent antileishmanial activities of these compounds such as terpenic derivatives, carvacrol, p-cymene, thymol, carvone, limonene, and terpinene [27-30]. Therefore, the presence of these phytoconstituents in P. khinjuk extract could be responsible for their antileishmanial effect though their exact mode of action is not clear. In the case of cytotoxic effects, the present findings showed that $P$. khinjuk alcoholic extract had no significant cytotoxic effects against J774 cells. Furthermore, SI value $\geq 10$ of $P$. khinjuk alcoholic extract demonstrated its safety against the macrophage cells and specificity to the parasite [19]. Thus, it can be suggested that P. khinjuk alcoholic extract is safe for mammalian cells.

In conclusion, the findings of the present study demonstrated that $P$. khinjuk alcoholic extract had potent antileishmanial activity and could control cutaneous leishmaniasis in mice infected with $L$. major. This result also provided the scientific evidence that natural plants could be used in the traditional medicine for the prevention and treatment of cutaneous leishmaniasis.

\section{Conflict of Interests}

The authors declare that there is no conflict of interests in this study.

\section{Acknowledgments}

This study was supported by the Razi Herbal Medicines Research Center and Vice Chancellor for Research, Lorestan University of Medical Sciences, Khorramabad, Iran (Grant no. 91/27).

\section{References}

[1] P. Desjeux, "Leishmaniasis: current situation and new perspectives," Comparative Immunology, Microbiology and Infectious Diseases, vol. 27, no. 5, pp. 305-318, 2004.

[2] World Health Organization, Control of the Leishmaniasis, vol. 949, WHO, Geneva, Switzerland, 2010.

[3] H. Mahmoudvand, M. Shakibaie, R. Tavakoli, S. Jahanbakhsh, and I. Sharifi, "In vitro study of leishmanicidal activity of biogenic selenium nanoparticles against Iranian isolate of sensitive and glucan-time-resistant Leishmania tropica," Iranian Journal of Parasitology, vol. 9, no. 4, pp. 452-460, 2014.

[4] D. O. Santos, C. E. R. Coutinho, M. F. Madeira et al., "Leishmaniasis treatment-a challenge that remains: a review," Parasitology Research, vol. 103, no. 1, pp. 1-10, 2008.

[5] J. Berman, "Clinical status of agents being developed for leishmaniasis," Expert Opinion on Investigational Drugs, vol. 14, no. 11, pp. 1337-1346, 2005.

[6] L. G. Rocha, J. R. G. S. Almeida, R. O. Macêdo, and J. M. Barbosa-Filho, "A review of natural products with antileishmanial activity," Phytomedicine, vol. 12, no. 6-7, pp. 514-535, 2005.

[7] P. Cos, A. J. Vlietinck, D. V. Berghe, and L. Maes, "Anti-infective potential of natural products: how to develop a stronger in vitro 'proof-of-concept"', Journal of Ethnopharmacology, vol. 106, no. 3, pp. 290-302, 2006.

[8] M. Bozorgi, Z. Memariani, M. Mobli, M. H. S. Surmaghi, M. R. Shams-Ardekani, and R. Rahimi, "Five pistacia species (P. vera, $P$. atlantica, P. terebinthus, $P$. khinjuk, and P. lentiscus): a review of their traditional uses, phytochemistry, and pharmacology," The Scientific World Journal, vol. 2013, Article ID 219815, 33 pages, 2013.

[9] V. Mozaffarian, Trees and Shrubs of Iran, Farhang Moaser, Tehran, Iran, 1st edition, 2005.

[10] K. Dimas, S. Hatziantoniou, J. H. Wyche, and P. Pantazis, "A mastic gum extract induces supression of growth of human 
colorectal tumor xenografts in immunodeficient mice," In Vivo, vol. 23, no. 1, pp. 63-68, 2009.

[11] H. Mahmoudvand, A. Sepahvand, S. Jahanbakhsh, B. Ezatpour, and S. A. A. Mousavi, "Evaluation of antifungal activities of the essential oil and various extracts of Nigella sativa and its main component, thymoquinone against pathogenic dermatophyte strains," Journal of Medical Mycology, vol. 24, no. 4, pp. e155e161, 2014.

[12] W. C. Evans, Trease and Evans Pharmacognosy, WB Saunders, 14th edition, 1998.

[13] H. Mahmoudvand, R. Tavakoli, F. Sharififar et al., "Leishmanicidal and cytotoxic activities of Nigella sativa and its active principle, thymoquinone," Pharmaceutical Biology, vol. 4, pp. 16, 2014.

[14] H. Mahmoudvand, F. Ezzatkhah, F. Sharififar et al., "Antileishmanial and cytotoxic effects of essential oil and methanolic extract of Myrtus communis L.," Korean Journal of Parasitology, vol. 53, no. 1, pp. 21-27, 2015.

[15] H. Mahmoudvand, F. Sharififar, I. Sharifi et al., "In vitro inhibitory effect of Berberis vulgaris (Berberidaceae) and its main component, berberine against different Leishmania species," Iranian Journal of Parasitology, vol. 9, pp. 28-36, 2014.

[16] OECD Guidelines for Testing of Chemicals, "Repeated dose dermal toxicity 21/28-day study," in OECD Guideline for Testing Chemicals, vol. 410, pp. 1-8, 1981.

[17] A. Salehabadi, M. Karamian, M. H. Farzad, and M. H. Namaei, "Effect of root bark extract of Berberis vulgaris L. on Leishmania major on BALB/c mice," Parasitology Research, vol. 113, no. 3, pp. 953-957, 2014.

[18] H. Nahrevanian, M. Farahmand, Z. Aghighi, M. Assmar, and A. Amirkhani, "Pharmacological evaluation of anti-leishmanial activity by in vivo nitric oxide modulation in Balb/c mice infected with Leishmania major MRHO/IR/75/ER: an Iranian strain of cutaneous leishmaniasis," Experimental Parasitology, vol. 116, no. 3, pp. 233-240, 2007.

[19] B. Weniger, S. Robledo, G. J. Arango et al., "Antiprotozoal activities of Colombian plants," Journal of Ethnopharmacology, vol. 78, no. 2-3, pp. 193-200, 2001.

[20] M. M. Cowan, "Plant products as antimicrobial agents," Clinical Microbiology Reviews, vol. 12, no. 4, pp. 564-582, 1999.

[21] A. R. McCutcheon, S. M. Ellis, R. E. W. Hancock, and G. H. N. Towers, "Antibiotic screening of medicinal plants of the British Columbian native peoples," Journal of Ethnopharmacology, vol. 37, no. 3, pp. 213-223, 1992.

[22] A. Shokri, I. Sharifi, A. Khamesipour et al., "The effect of verapamil on in vitro susceptibility of promastigote and amastigote stages of Leishmania tropica to meglumine antimoniate," Parasitology Research, vol. 110, no. 3, pp. 1113-1117, 2012.

[23] R. Lira, S. Sundar, A. Makharia et al., "Evidence that the high incidence of treatment failures in Indian kala- azar is due to the emergence of antimony-resistant strains of Leishmania donovani," Journal of Infectious Diseases, vol. 180, no. 2, pp. 564$567,1999$.

[24] M. Taran, M. Mohebali, and J. Esmaeli, "In vivo efficacy of gum obtained Pistacia atlantica in experimental treatment of cutaneous leishmaniasis," Iranian Journal of Public Health, vol. 39, no. 1, pp. 36-41, 2010.

[25] P. K. Lai and J. Roy, "Antimicrobial and chemopreventive properties of herbs and spices," Current Medicinal Chemistry, vol. 11, no. 11, pp. 1451-1460, 2004.
[26] I. Orhan, M. Aslan, B. Sener, M. Kaiser, and D. Tasdemir, "In vitro antiprotozoal activity of the lipophilic extracts of different parts of Turkish Pistacia vera L.," Phytomedicine, vol. 13, no. 910, pp. 735-739, 2006.

[27] J. O. de Melo, T. A. Bitencourt, A. L. Fachin et al., "Antidermatophytic and antileishmanial activities of essential oils from Lippia gracilis Schauer genotypes," Acta Tropica, vol. 128, no. 1, pp. 110115, 2013.

[28] R. D. Pearson, A. A. Manian, D. Hall, J. L. Harcus, and E. L. Hewlett, "Antileishmanial activity of chlorpromazine," Antimicrobial Agents and Chemotherapy, vol. 25, no. 5, pp. 571-574, 1984.

[29] J. S. Tandon, V. Srivastava, and P. Y. Guru, "Iridoids: a new class of leishmanicidal agents from Nyctanthes arbortristis," Journal of Natural Products, vol. 54, no. 4, pp. 1102-1104, 1991.

[30] L. Monzote, M. García, J. Pastor et al., "Essential oil from Chenopodium ambrosioides and main components: activity against Leishmania, their mitochondria and other microorganisms," Experimental Parasitology, vol. 136, no. 1, pp. 20-26, 2014. 


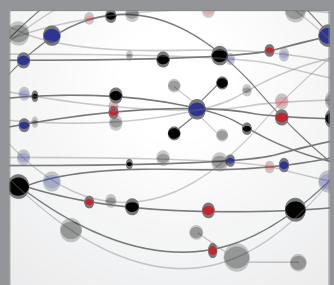

The Scientific World Journal
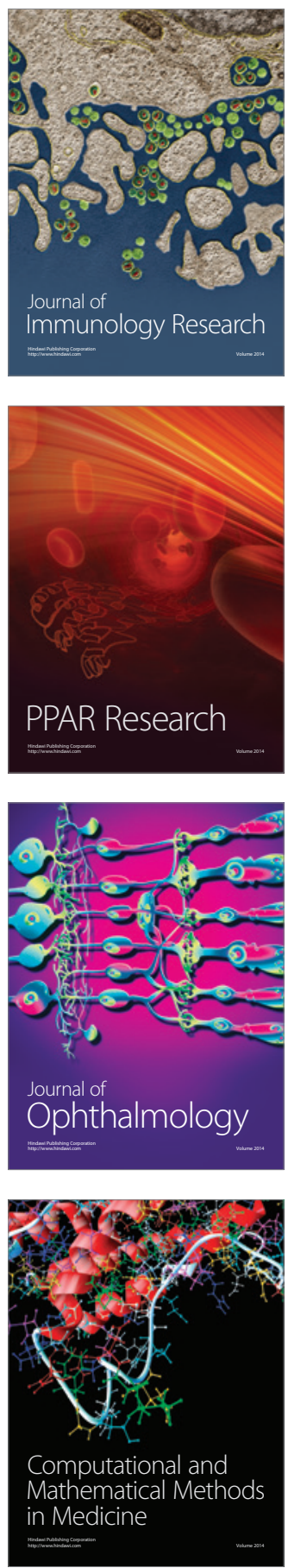

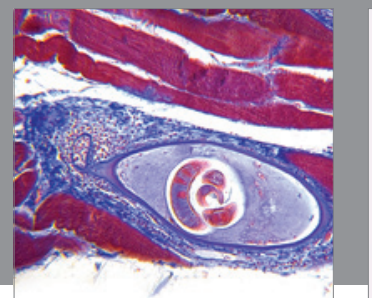

Gastroenterology

Research and Practice
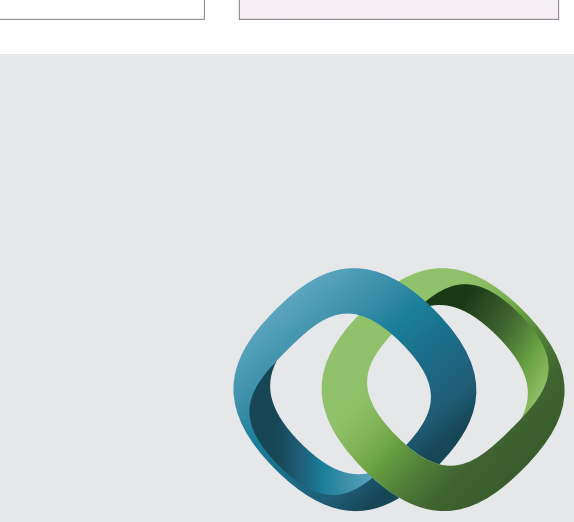

\section{Hindawi}

Submit your manuscripts at

http://www.hindawi.com
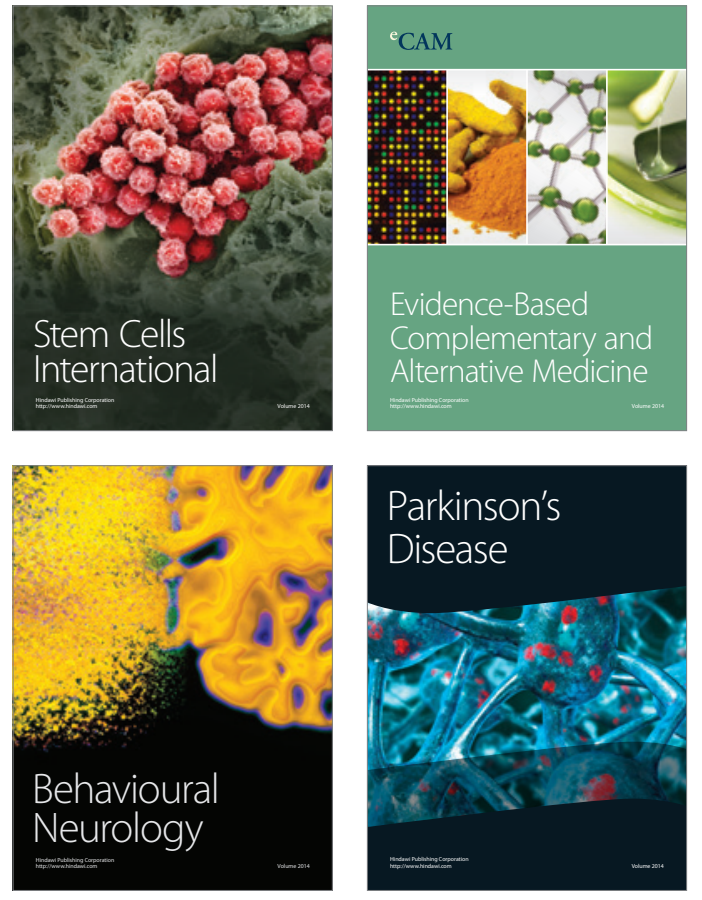
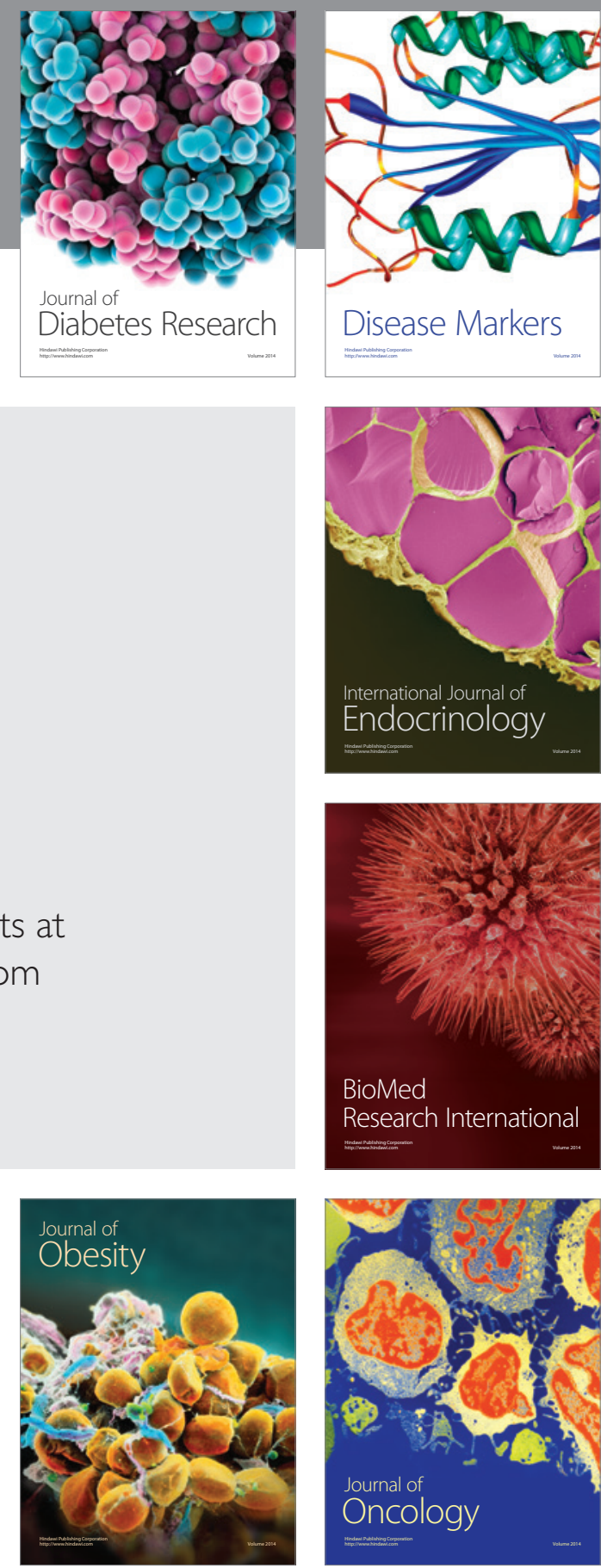

Disease Markers
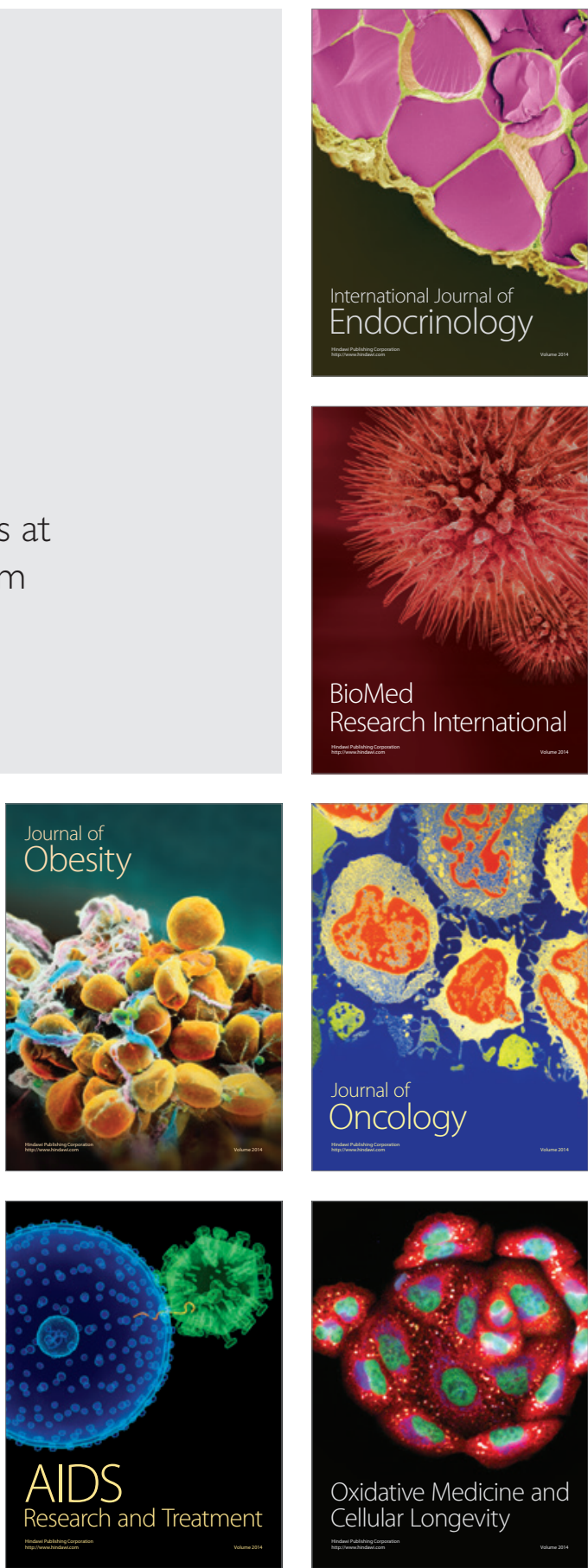